\title{
Conflict of interest explains the size of student evaluation of teaching and learning correlations in multisection studies: a meta-analysis
}

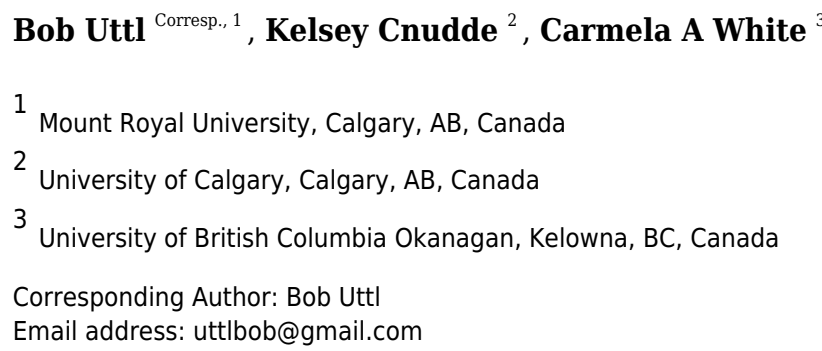

We examined the associations between the size of student evaluation of teaching and learning (SET/learning) correlations and presence of several conflicts of interest (COIs) including corporate, administrative, evaluation unit, SET author, and funder interests. Our meta-analyses of SET/learning correlations reported by multisection studies show that researchers with a vested interest in finding large positive SET/learning correlations found, on average, large positive SET/learning correlations. In contrast, researchers with no identifiable COls found that SET/learning correlations were zero or nearly zero. The largest SET/learning correlations were reported by authors with ties to SET selling corporations. Smaller but still substantial SET/learning correlations were reported by researchers with administrative assignments and by researchers in evaluation units/departments responsible for the administration of SET. Moreover, authors with the most significant COIs were publishing their studies primarily prior to 1981 whereas authors with no or less significant COls were publishing their studies in 1981 or afterwards. Studies published prior to 1981 reported small but significant $(r=.31) \mathrm{SET} /$ learning correlations whereas studies published in 1981 and after reported near zero, non-significant SET/learning correlations ( $r$ $=.06)$. The presence of COls was associated with earlier publication date but also with smaller samples. Finally, whereas corporate, administrative, and evaluation unit authors nearly ceased publishing multisection studies on SET/learning correlations, authors from business and economics departments are now responsible for the substantial portion of newer, larger, and higher quality studies published in 1981 and after. 
1

2

3

4

5

6

7

8

9

10

11

12

13

14

15

16

17

18

19

20

21

22

23

24

25

26

27

28

29

30

31

32

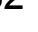

Conflict of interest explains the size of student evaluation of teaching and learning correlations in multisection studies: a meta-analysis

Bob Uttl ${ }^{1}$, Kelsey Cnudde ${ }^{2}, \&$ Carmela A. White ${ }^{3}$

${ }^{1}$ Mount Royal University, Calgary, AB, Canada

${ }^{2}$ University of Calgary, Calgary, AB, Canada

${ }^{3}$ University of British Columbia Okanagan, Kelowna, BC, Canada

Corresponding Author:

Bob Uttl ${ }^{1}$

Email address: uttlbob@gmail.com 
Abstract

34

35 We examined the associations between the size of student evaluation of teaching and learning 36 (SET/learning) correlations and presence of several conflicts of interest (COIs) including 37 corporate, administrative, evaluation unit, SET author, and funder interests. Our meta-analyses of 38 SET/learning correlations reported by multisection studies show that researchers with a vested 39 interest in finding large positive SET/learning correlations found, on average, large positive 40 SET/learning correlations. In contrast, researchers with no identifiable COIs found that 41 SET/learning correlations were zero or nearly zero. The largest SET/learning correlations were 42 reported by authors with ties to SET selling corporations. Smaller but still substantial

43 SET/learning correlations were reported by researchers with administrative assignments and by 44 researchers in evaluation units/departments responsible for the administration of SET. Moreover, 45 authors with the most significant COIs were publishing their studies primarily prior to 1981 46 whereas authors with no or less significant COIs were publishing their studies in 1981 or 47 afterwards. Studies published prior to 1981 reported small but significant $(r=.31) \mathrm{SET} /$ learning 48 correlations whereas studies published in 1981 and after reported near zero, non-significant 49 SET/learning correlations $(r=.06)$. The presence of COIs was associated with earlier publication 50 date but also with smaller samples. Finally, whereas corporate, administrative, and evaluation 51 unit authors nearly ceased publishing multisection studies on SET/learning correlations, authors 52 from business and economics departments are now responsible for the substantial portion of 53 newer, larger, and higher quality studies published in 1981 and after. 
58

59

60

61

62

63

64

65

66

67

68

69

70

71

72

73

74

75

76

77

78

79

80

81

82

83

84

85

86

87

88

89

90

91

92

93

94

95

96

97

For decades, colleges and universities have been asking students to evaluate the teaching effectiveness of their professors using a variety of Student Evaluation of Teaching (SET) questionnaires based on a widespread belief that students learn more from more highly rated professors. The SET are typically administered during the last few weeks of classes, before students receive their final grades, and they ask students to rate their professors' teaching, for example, their overall teaching effectiveness as well as their knowledge, clarity, organization, friendliness, fairness, approachability, availability, etc. The SET ratings for each course/class are summarized, often by calculating means for each rated item and across all items, and the mean SET ratings are then used as a measure of professors' teaching effectiveness. The SET ratings are subsequently used for a variety of high stakes personnel decisions such as faculty hiring, firing, promotion, tenure, merit pay, teaching awards, and distinguished professor awards (Spooren, Brockx, \& Mortelmans, 2013; Stark \& Freishtat, 2014; Uttl, White, \& Gonzalez, 2017; Wachtel, 1998).

The main evidence cited for the belief that students learn more from professors with higher SET ratings are several meta-analyses of multisection studies showing small-to-moderate correlations between SET ratings and student learning (Uttl et al., 2017). For example, P. A. Cohen (1981) claimed that the correlation between overall instructor SET ratings and learning was .43 to .44 . Similarly, Feldman (1989) claimed that the correlations between various SET item ratings and learning were as high as .57 . These meta-analyses were reviewed by numerous researchers who all concluded that these meta-analyses are strong evidence of the validity of SET ratings as a measure of student learning. For example, Abrami and d'Apollonia (1999, p. 519) wrote: "[SET] ratings explain instructor impact on student learning to a moderate extent (corrected $r=.47$ )". Marsh (Marsh, 2007, p. 339) wrote: "Perhaps more than any other area of SET research, results based on the multisection validity paradigm support the validity of SET". Benton and Cashin (2012, p. 4) wrote: "the multisection studies show that classes in which the students gave the instructor higher ratings tended to be the ones where the students learned more". Not surprisingly, these summary reviews then made their way as established facts into various self-help books for new faculty members. For example, Davis (2009, p. 534) wrote: "Students of highly rated teachers achieve higher final exam scores, can better apply course material, and are more inclined to pursue the subject subsequently."

Recently, Uttl and colleagues (2017) published a detailed review of all previously published meta-analyses on SET/learning correlations and found that they all suffered from multiple critical methodological shortcomings. For example, none of these meta-analyses adequately considered the possibility that their results may be an artifact of a small sample bias even though the smallest studies (with 5 sections) showed correlations as high as .91, whereas the larger studies (with 30 or more sections) showed much smaller correlations. The substantial relationship between the sample size and the size of the SET/learning correlations would have been obvious to anyone who plotted the data (Uttl et al., 2017). Moreover, the previous metaanalyses did not adequately describe the search for and identity of all primary studies, often did not provide effect sizes and sample sizes for each primary study, often failed to weigh 
98 SET/learning correlations by sample size, and in general, were so poorly described as to be 99 unreplicable. In one remarkable review of previous meta-analyses, Abrami, P. A. Cohen and 100 d'Apollonia (1988) were concerned about "disparate conclusions of the [multisection study]

101

102

103

104

105

106

107

108

109

110

111

112

113

114

115

116

117

118

119

120

121

122

123

124

125

126

127

128

129

130

131

132

133

134

135

136

137

reviews" (p. 151), discussed "why the reviews differ" (p. 155), and even considered the possibility of a publication bias (one type of small-sample bias) but then dismissed it. They puzzled over "troublesome" (p. 160) disagreement between SET/learning correlations extracted by P. A. Cohen (1983) and McCallum (1984). However, instead of checking the extracted values against the primary studies and determining the source of the disagreement, Abrami et al. chose to speculate about possible sources of disagreement. As Uttl et al. (2017) found, the principal reason for the "troublesome" disagreement was McCallum's (1984) failure to correctly extract relevant values from the primary studies.

When Uttl et al. (2017) re-analyzed the previously published meta-analyses of multisection studies, they found that the previous findings were artifacts of small sample biases. The small sample size studies showed large SET/learning correlations whereas the large sample size studies showed no or only minimal SET/learning correlations. When the small sample bias was taken into account through a variety of meta-analytic methods, the estimated SET/learning correlations were much smaller than previously reported. Moreover, given the shortcomings of the previous meta-analyses, Uttl et al. conducted a new up-to-date meta-analysis of the SET/learning correlations from multisection studies. Their search yielded 51 articles with 97 multisection studies. Using limit meta analysis to adjust for the prevalence of small sample bias, the new data set resulted in a SET/learning correlation of only $r=.12,95 \% \mathrm{CI}=[.03, .21]$. Moreover, when the same analyses was re-run but only with data from studies with prior knowledge/ability adjustments, the limit meta-analysis resulted in a SET/learning correlation of $r$ $=-.06,95 \% \mathrm{CI}=[-.17, .07]$. Accordingly, Uttl et al. concluded that the data from multisection studies do not support the claims that students learn more from more highly rated professors. Rather, the results from multisection studies provide evidence that SET ratings and learning are unrelated.

Why is it that for three to four decades fatally flawed meta-analyses of multisection studies by P. A. Cohen (1981) and Feldman (1989) have been cited as evidence of SET/learning correlations, and that SET ratings are considered valid enough to be used for making high stakes personnel decisions, including for terminating people's careers? How is it possible that experts who reviewed these meta-analyses did not notice major red flags in previous meta-analyses of multisection studies (e.g., not reporting SET/learning correlations and sample sizes for primary studies, not weighing SET/learning correlations by sample size), or in the primary studies themselves (e.g., impossibly high correlations in small sized primary studies)? How is it possible that when experts noticed "troublesome" disagreements between the SET/learning correlations in different meta-analyses they did not follow up and identify the source of the disagreements and instead chose to speculate about them?

One possibility, we investigated for this article, is that the primary findings and the reviews of SET/learning correlations have been distorted by conflicts of interest (COI). One of

Peer) reviewing PDF | (2018:10:32121:3:1:NEW 29 May 2019) 
138 the widely accepted definitions states that "a conflict of interest is a set of circumstances that

139

140

141

142

143

144

145

146

147

148

149

150

151

152

153

154

155

156

157

158

159

160

161

162

163

164

165

166

167

168

169

170

171

172

173

174

175

176

177

creates a risk that professional judgments or actions regarding a primary interest will be unduly influenced by a secondary interest" (Institute of Medicine (US) Committee on Conflict of Interest in Medical Research, Education, and Practice, 2009, p. 46). Consistent with this definition, when using SET ratings for making high stakes personnel decisions, the 'primary interests' include the promotion and safeguarding of the integrity of research, the validity of scientific findings and conclusions, the welfare of those to whom the scientific findings are applied, and the welfare of the society that relies on those scientific findings. In contrast, secondary interests include direct financial gains by individual researchers such as profits, dividends, salaries, and other financial benefits. Secondary interests are also non-financial benefits such as efficient time-saving evaluations and management of faculty by chairs and deans, approval and praise from upper levels of the university administration, greater potential for administrative advancement, and the appearance of objectivity and public accountability (Uttl et al., 2017). Although the financial benefits are often easier to determine and quantify objectively, the non-financial benefits may not be any less damaging to the primary interests. Importantly, by the definition above, a COI exists independently of an individual actually being influenced by a secondary interest. A COI is a set of circumstances that increases the risk of undue influence (Institute of Medicine (US) Committee on Conflict of Interest in Medical Research, Education, and Practice, 2009).

The risk that the primary research findings on SET and the written reviews were influenced by COIs seems substantial. First, even a superficial glance makes it apparent that many multisection studies were authored by researchers who work for or own corporations that sell SET systems. For example, John Centra was heavily involved in the development of the Student Instructional Report (SIR) and SIR-II SET system by the Educational Testing Service (Centra, 1977, 2015); Peter Frey developed the Endeavor Instructional Rating Card and founded Endeavor Information Systems, Inc. (The Endeavor Handbook, n.d.); Herbert Marsh developed the Student Evaluation of Educational Quality (SEEQ) SET system, and he founded and became President of Evaluation, Testing and Research, Inc. (Marsh, Fleiner, \& Thomas, 1975); and Lawrence Aleamoni developed the Aleamoni Course/Instructor Evaluation Questionnaire (CIEQ), and he founded and became President of Comprehensive Data Evaluation Services Inc (CODES, Inc.) (Armen, 2016; Hill, 2006), and CODES Inc. presently sells CIEQ through www.cieq.com. Second, the experts who reviewed the previous meta-analyses of multisection studies and found that the meta-analyses provide strong evidence of the validity of SET as a measure of teaching effectiveness had strong interests in that particular conclusion. For example, P. A. Cohen's (1981) meta-analysis, the first and the most highly cited meta-analysis of multisection studies claiming that SET/learning correlations were greater than $r=.40$, was based on P. A. Cohen's (1980) dissertation. P. A. Cohen's dissertation was co-supervised by James A. Kulik and Wilbert J. McKeachie, known proponents of SET rating who concluded that SET/learning correlations were small to moderate in their published narrative reviews of the same literature prior to P. A. Cohen's work (P. A. Cohen, 1981). Moreover, Kulik was an

Peer) reviewing PDF | (2018:10:32121:3:1:NEW 29 May 2019) 
178 Associate Director, Center for Research on Learning and Teaching, University of Michigan 179 (Kulik, Kulik, \& Cohen, 1980); P. A. Cohen became Research Associate in the same center by 180 Fall 1980 after completing his dissertation (Kulik et al., 1980); and by the time he published his 181 meta-analysis in 1981 he was an Assistant Director of the Office of Instructional Services and 182 Educational Research, Dartmouth College (P. A. Cohen, 1981). Benton worked for the IDEA 183 Center, a nonprofit organization selling the IDEA SET to colleges and universities worldwide (S. 184 L. Benton \& Cashin, 2012). Marsh and Aleamoni, as noted above, both developed their own SET 185 systems and founded their own companies to distribute them. Third, a number of authors of 186 multisection studies worked for units or departments responsible for the evaluation of faculty 187 teaching effectiveness in various colleges and universities. Finally, some multisection studies were funded by grants from corporations with vested interests, for example, Endeavor Information Systems Inc..

Notably, COIs tying authors to their SET enterprises were often not declared and readers may not know about them. For example, we only found out that Aleamoni was the president of Comprehensive Data Evaluation Services Inc. -- a corporation that publishes and distributes Aleamoni's CIEQ SET -- by discovering the case Aleamoni v. Commissioner of Internal Revenue Service where this information is disclosed (Armen, 2016). He, his wife, and his children owned $100 \%$ of shares in this company.

Moreover, even though Clayson's (2009) findings are uninterpretable and his conclusions unwarranted (Uttl et al., 2017), Clayson (2009) suggested that the magnitude of SET/learning correlations may vary by publication year, authors' department, and other factors. Our own review of multisection studies suggests that, in addition to study size and a variety of COIs,

200 SET/learning correlations may be larger for studies published prior to P. A. Cohen's (1981)

201

202 meta-analysis compared to those published after, as well as studies originating from education or

203

204

205

206

207

208

209 psychology departments vs. studies originating from business and economics departments. In general, studies published prior to 1981 were conducted primarily by SET corporations and evaluation units, whereas studies published after 1981 were conducted primarily by authors from business and economics departments.

Accordingly, the current study had several main goals. The first goal was to determine whether SET/learning correlations reported in primary studies were larger for studies published prior to 1981 vs. 1981 and after. P. A. Cohen's (1981) meta-analysis appeared to have cemented a belief that SET/learning correlations were substantial. However, as noted above, a majority of studies published prior to 1981 were published by authors with corporate, administrative, and evaluation unit COIs, and thus, to the extent to which COIs play a role, we would expect the earlier studies to report larger SET/learning correlations. In addition, earlier vs. later studies

214

215

216 employed smaller samples, and thus, in combination with publication bias, earlier studies are likely to report larger SET/learning correlations. The second goal was to examine whether SET/learning correlations reported by authors with the most significant COI -- authors working for or owning SET selling corporations -- are larger than correlations reported by other authors. We expected that the corporate COIs would result in the largest SET/learning correlations. The 
218 third goal was to examine the size of the SET/learning correlations by the type of COI:

219 corporate, administrative, evaluation unit, SET author and funder COIs. We made the following

220 predictions as to which of these COIs would result in larger vs. smaller COI effects: (a) we

221 expected the corporate COIs to result in the strongest effect, (b) we expected all COIs to have

222 some effect, (c) we expected the SET author COI alone to have some but a weaker effect than

223 the SET author COI combined with the corporate, administrative, or evaluation unit COI, (d) we

224 expected the evaluation unit COI to be more significant that the SET author COI alone, and (e)

225 we expected the administrative COI be similar to the evaluation unit COI but perhaps stronger

226 given the administrations' need to evaluate faculty, and in particular, to do it efficiently,

227 inexpensively, and with aura of numerical objectivity. The fourth goal was to examine the

228 associations between SET/learning correlations and authors' place of employment/work

229 including corporate, administrative, evaluation unit, education and psychology departments,

230 business and economics departments, and other. With respect to authors' departments, our

231 analyses were purely exploratory and aimed to examine Clayson's (2009) suggestion that

232 SET/learning correlations reported by authors from the education and liberal arts disciplines are

233 larger than those reported by authors from business/economics departments. Our final goal was

234 to explore if SET/learning correlations vary with the number of COIs that are present. Although

235 COIs are unlikely to have similar or a strictly additive effect, we expected studies with a greater

236 number of COIs to result in the larger SET/learning correlations. For example, as noted above, a

237 SET author who established a corporation to sell his or her SET system is likely to have more

238 substantial overall COI than a SET author who did not commercialize his or her SET system and

239 had no other COI.

240

241

242 A preliminary review of the all available multisection studies revealed that the articles

243 themselves rarely declared any conflicts of interest and often failed to even disclose sufficient

244 information to determine whether any conflict of interest might exist. Accordingly, to determine

245 the presence of any conflict of interest, we adopted the method detailed in a recent investigation

246 of COIs and their relationship to outcomes in randomized controlled trials (Ahn et al., 2017).

247 We proceeded in three steps. First, we examined each article reporting a multisection study.

248 Second, we examined all articles published by the study authors within five years of the

249 multisection study publication date. Third, we searched Google for author's CVs, and other

250 relevant publications.

$251 \quad$ For each multisection study reported in Uttl et al. (2017), we coded for the presence or

252 absence of any of the following direct and indirect conflicts of interest:

253 Corporate interest. If at least one author worked for a corporation or organization

254 selling SET services (e.g., Educational Testing Service, IDEA), the corporate interest was coded 255 as present.

256 Evaluation unit interest. If at least one author worked for a corporate or university

257 teaching evaluation unit, the evaluation unit interest was coded as present. 
258

259

260

261

262

263

264

265

266

267

268

269

270

271

272

273

274

275

276

277

278

279

280

281

282

283

284

285

286

287

288

289

290

291

292

293

294

295

296

297

Administrative conflict of interest. If at least one author was an administrator who was likely to be directly responsible for evaluation of faculty serving under the administrator, for example, a chair of the department or a dean, the administrative interest was coded as present.

SET author interest. If at least one author authored or co-authored a more widely used SET (i.e., SET used more widely than in one particular study), the SET author interest was coded as present.

Funder interest. If a funding organization had a direct conflict of interest (e.g., when SET corporation funded the study), the funder interest was considered present. Conversely, the funder interest was considered absent if a study was funded from granting agencies such as NSF or the Kellogg's Foundation that are not known to have any identifiable interest in the use of SET systems.

Department type. Each author's department was classified as one of the following: corporate unit, evaluation unit, education or psychology department, business or economics department, and other/unknown depending on author affiliation stated in the publication itself.

Two independent coders coded COIs using the method described above and any disagreements were resolved by discussion and consensus. The agreement between the two coders was assessed by Cohen's kappa. Cohen's kappa ranges from - 1 to 1 with 1 indicating perfect agreement, 0 chance agreement, and -1 perfect disagreement. In general, values 0.0 to 0.2 indicated slight agreement, 0.21 to 0.40 fair agreement, 0.41 to 0.60 moderate agreement, 0.61 to .80 substantial agreement, and 0.81 to 1 almost perfect agreement (Hallgren, 2012).

We examined the effects of publication period, COIs, and authors' department using the random effect model (using restricted maximum-likelihood estimator or REML and Fisher's z transformation of correlations) with specific moderators. All reported analyses were conducted using R (version 3.4.4) (R Core Team, 2018), and more specifically, using packages meta (version 4.9-2), metafor (version 2.0-0), metasens (0.3-2), and wPerm (version 1.0.1). One may argue that the assumption of bivariate normality required for our analyses is unlikely to have been satisfied. However, a number of studies have found that random effect meta-analysis estimates, including confidence interval estimates, are robust to even severe violations of the bivariate normality assumption (Kontopantelis \& Reeves, 2012). Alternatively, our data could be analyzed using permutation tests. However, permutation tests are not suitable because they do not take into account differences in sample sizes of the primary studies. Nevertheless, our reanalyses of the data using permutation tests yielded similar results.

\section{Results}

Table 1 shows all 97 multisection studies included in Uttl et al.'s (2017) meta-analysis, with each study size $(n)$ and SET/learning correlation for instructor $(r)$ taken from Uttl et al.'s Table 2. The table includes a column showing the presence or absence of each conflict of interest: corporate (Corp), administrative (Admin), evaluation unit (Eval U.), SET author (SET Auth.), funder (Funder), and the total count of all COIs present for each study (i.e., the sum of corporate, administrative, evaluation unit, SET author, and funder interests). In addition, the 
298

299

300

301

302

303

304

305

306

307

308

309

310

311

312

313

314

315

316

317

318

319

320

321

322

323

324

325

326

327

328

329

330

331

332

333

334

335

336

337

table includes a column indicating whether or not authors were from education or psychology (E/Psy), or from business or economics departments (B/Econ). Inter-rater reliability measured by Cohen's kappa was nearly perfect; Cohen's kappa was 1.00 for corporate COI, 0.94 for administrative COI, 1.00 for evaluation unit COI, 0.98 for SET author COI, and 0.88 for funder COI. Any discrepancies between the two coders were discussed until a consensus was achieved and the consensus data are reported in Table 1.

Table 2 shows the means, $S D$ s, and a matrix of the simple correlations among all variables including the COIs, department memberships, SET/learning correlation, study size, and publication period. The means indicate that one of the COIs -- the funder COI - was rare, present in only 4\% (4 out of 97) of the studies. The correlation matrix indicates that studies published in 1981 and after were associated with a lower prevalence of COIs and a higher involvement of business and economics departments. Importantly, the correlation matrix also indicates that some COIs frequently co-occurred with other COIs. More detailed analyses revealed that out of 30 studies with the SET author COI, 15 studies included the corporate COI, and out of the remaining 15 studies with the SET author COI, 6 studies included the administrative COI, 6 studies included the evaluation unit COI, 1 study included the funder COI, and only 2 studies included no other COI. Most critically, the size of SET/learning correlations was associated with publication period (studies published in 1981 and after reported lower SET/learning correlations), and with corporate COIs, SET author COIs, and COI count.

Figure 1, top left panel, shows the magnitude of SET/learning correlations as a function of multisection study size (Uttl et al., 2017). This figure shows that (1) the number of sections included in multisection studies was generally small with many studies based on as few as five sections, (2) many studies reported impossibly high correlations, and (3) the magnitude of SET/learning correlations decreased for larger sized studies (Uttl et al., 2017). Figure 1, top right panel, shows the histogram of multisection studies by publication year. A large number of studies was published just prior to P. A. Cohen's (1981) meta-analysis and a relatively smaller number of studies have been published since then. Figure 1, bottom left panel, shows the number of studies published prior to 1981 and since then by origin of the study. Prior to 1981, most studies were published by authors from SET corporations, evaluation units, administration, and education and psychology departments. In contrast, since 1981, most studies were published by authors from business and economics departments and psychology departments. No studies were published by authors from SET corporations or from evaluation units. Figure 1, bottom right panel, shows the study size as a function of publication year. SET/learning correlations reported by studies published prior to 1981 vs. since then used smaller samples. That is, most studies published prior to 1981 used very small samples and larger samples became more common only after 1981.

Figure 2, top left panel, shows the size of SET/learning correlations as a function of publication date, prior to 1981 vs. 1981 and after. Each dot represents one SET/learning correlation superimposed on the boxplot of their distribution. Studies published prior to 1981 reported much larger SET/learning correlations than studies published in 1981 and after. The 
338

339

340

341

342

343

344

345

346

347

348

349

350

351

352

353

354

355

356

357

358

359

360

361

362

363

364

365

366

367

368

369

370

371

372

373

374

375

376

377

random effect meta-analysis (using z-transformed correlations and REML estimation method) with publication period as a moderator showed significant differences between SET/learning correlations reported by studies published prior to 1981 and studies published 1981 and after, $Q(1)=10.31, p=.0013$. For the 69 studies published prior to $1981, r=.31,95 \% \mathrm{CI}=[.22, .39]$, $I^{2}=53.1 \%$ whereas for 28 studies published in 1981 or after, $r=.06,95 \% \mathrm{CI}=[-.07, .19], I^{2}=$ $19.2 \%$.

Figure 2, top right panel, shows boxplots of SET/learning correlations by authors' associations with SET corporations. SET/learning correlations were much larger when at least one author was associated with a SET corporation. The random effect meta-analysis (using ztransformed correlations and REML estimation method) with corporate $\mathrm{COI}$ as a moderator showed significant differences between SET/learning correlations reported by studies with vs. without corporate COI, $Q(1)=15.38, p<.0001$. For the 15 studies with corporate COI, the correlation was $r=.58,95 \% \mathrm{CI}=[.41, .71], I^{2}=5.8 \%$, whereas for the 82 studies without corporate COI, the correlation was $r=.18,95 \% \mathrm{CI}=[.10, .25], I^{2}=52.7 \%$.

Figure 2, bottom left panel, shows boxplots of SET/learning correlations by authors' associations with SET corporations, administration, evaluation units, and authoring SET. For these analyses, studies were assigned to categories by the highest, most significant COI present in the following order: corporate, administrative, evaluation unit, SET author, and no identified COI. This ordering was determined based on (a) our a priori expectations detailed in the introduction, (b) the findings that COIs frequently co-occurred, as detailed above, and rendered the comparative analyses of single COI effects impossible, (c) the finding that the funder COI was rarely present and when present it typically co-occurred with the corporate COI, and (d) our guess that the administrative $\mathrm{COI}$ might be stronger than the evaluation unit COI given that administrative interests are frequently cited as one of the key reasons for the widespread use of the SET. As the panel shows, the corporate COI was associated with the largest effects, the administrative COI with the next largest effects, the evaluation unit COI with smaller effects, the SET author COI with a still smaller effects, and the smallest effects were reported by studies with no known COI. The random effect meta-analysis with COI degree as a moderator showed significant differences between the groups of studies, $Q(4)=28.54, p<.0001$. Table 3 highlights that corporate COI resulted in the largest effect of $r=.57$, administrative COI in $r=.33$, evaluation unit COI in $r=.25$, SET author COI in $r=.15$, and no known COI in $r=.06$. Neither the SET author COI (alone) nor the 'no known COI' estimates significantly differed from zero. We have also examined the association between SET/learning correlations and the specific ordering of COI categories above using a permutation relationship test (using R package wPerm), with 9,999 replications and Spearman's rank correlation method. Correlation between SET/learning correlations and the ordering of COI categories was moderately strong, $r=.45, p<$ .001. Because we did not specify the relative order of the administrative and the evaluation unit COI categories apriori, we repeated the permutation test with the order of these two COI categories reversed. Correlations was nearly identical, $r=.41, p<.001$.

Figure 2, bottom right panel, shows boxplots of SET/learning correlations by authors' 
378

379

380

381

382

383

384

385

386

387

388

389

390

391

392

393

394

395

396

397

398

399

400

401

402

403

404

405

406

407

408

409

410

411

412

413

414

415

416

417

associations with SET corporations, administration, evaluation units, psychology/education departments, business/economics departments, and other departments. Similarly to the previous analysis, the highest level of association was used to categorize studies. The figure highlights that authors associated with education and psychology, and with business and economics, reported similar SET/learning correlations when authors involved in administration and in evaluation units were classified in administration and evaluation units rather than as ordinary members of their departments. The random effect meta-analysis with authors' association as a moderator showed significant differences between the groups of studies, $Q(5)=33.82, p<.0001$. Table 4 highlights that authors associated with education and psychology reported $r=.15$, authors associated with business and economics reported $r=-.04$, and authors with no known associations reported $r=.16$.

Figure 3 shows boxplots of SET/learning correlations by the total number of COIs identified for each study. The figure highlights that studies with no COIs reported on average nearly zero SET/learning correlations whereas studies with 1, 2, or 3 COIs reported on average small to moderately large SET/learning correlations. The random effect meta-analysis with the number of COIs as a moderator showed significant differences between the groups of studies, $Q(3)=22.35, p<.0001$. Table 5 highlights that studies with no identifiable COI resulted in estimated $r=.06$ whereas studies with the most COIs resulted in estimated $r=.53$. We have examined an association between SET/learning correlations and a number of COIs using permutation relationship test (using R package wPerm), with 9,999 replications and Spearman's rank correlation method. Correlation between SET/learning correlations and a number of COIs was moderately strong, $r=.39, p<.001$.

\section{Discussion}

Researchers with a COI found, on average, large positive SET/learning correlations. In contrast, researchers with no identifiable COIs found that SET/learning correlations were zero or nearly zero. As predicted, the largest SET/learning correlations were reported by authors with ties to corporations that sell SET systems. Smaller but still substantial SET/learning correlations were reported by researchers with administrative assignments and with evaluation units/departments responsible for the administration of SET. Moreover, authors with the most significant COIs were publishing their studies primarily prior to 1981 whereas authors with no or less significant COIs were publishing their studies in 1981 or afterwards. Studies published prior to 1981 reported small but significant $(r=.31) \mathrm{SET} /$ learning correlations whereas studies published in 1981 and after reported near zero, non-significant SET/learning correlations $(r=$ .06). As our analyses show, the presence of COIs was associated with earlier publication date but also with smaller samples. Finally, whereas corporate, administrative, and evaluation unit authors nearly ceased publishing multisection studies on SET/learning correlations, authors from business and economics departments are now responsible for a substantial portion of newer, larger, and higher quality studies published since 1981.

Our findings are striking but at the same time not surprising. As Ahn et al. (2017) 
418 recently showed, even effects reported in randomized clinical trials -- a gold standard of 419 experimental design used to determine the effectiveness of therapies -- are correlated with 420 authors' conflict of interest. When a principal investigator has financial ties with a drug 421 manufacturer, a study was more than three times as likely to report positive drug effects than

422

423

424

425

426

427

428

429

430

431

432

433

434

435

436

437

438

439

440

441

442

443

444

445

446

447

448

449

450

451

452

453

454

455

456

457 when the principal investigator had no such financial ties. Just like drug manufacturers, SET corporations need to sell SET systems to as many universities and colleges as they can, as their profits as well as their presidents', scientists', and employees' salaries depend on such sales. SET corporations reporting that SET/learning correlations are low or near zero would terminate their SET related revenues and reasons for their existence. Similarly, evaluation units need to show their value to the administration and reporting that SET ratings do not correlate with learning may result in the demise of these units. Moreover, as argued previously, administrators need inexpensive and efficient ways to evaluate faculty and if administrators report that SET do not correlate with learning they could not justify using the use of such ratings. In turn, they would have to search for more costly and more demanding alternative ways to evaluate faculty's teaching effectiveness. To start with, they would have to figure out what effective teaching is, something that educators were unable to establish despite decades of sustained efforts, and how to measure effective teaching both reliably and with a high degree of validity necessary for making high stakes personnel decisions (Uttl et al., 2017). This definition and measurement problem has been brought to the forefront by a recent arbitration decision in Ryerson University v. Ryerson Faculty Association (2018 CanLII 58446) where an arbitrator ordered Ryerson University "to ensure that FCS [Ryerson's acronym for SET] results are not used to measure teaching effectiveness in promotion or tenure."

Finally, the COI influence on SET research findings is likely facilitated by a general lack of transparency and openness evidenced in this literature. SETs are typically not made public and only SET corporations, evaluation units, and administrators have access to SET data. As a result, the findings originating from the SET corporations, evaluation units, and administrators cannot be examined and verified by independent researchers. Given that most authors did not disclose COIs and their COIs had to be determined by searching other publicly available sources, it is likely that we missed some COI ties and, in turn, this may have underestimated the strength of associations between COIs and the reported SET/learning correlations. In future studies, it is desirable that authors declare COIs clearly and with specificity within each study. Importantly, requirements for authors to declare COIs have become more strict and explicit over the years and this ought to facilitate the detection of COIs. Similarly, requirements for transparency have also became more prominent, with some journals (e.g., PLOS, PeerJ) requiring data to be publicly posted prior to an article publication, thus providing instantaneous opportunities for other researchers to examine reported analyses and findings.

Our findings suggest that COIs, including corporate and administrative interests, had a major influence on findings of multisection studies, especially the findings of multisection studies published prior to 1981, prior to P. A. Cohen's (1981) meta-analysis that concluded that SET/learning correlations were substantial. When P. A. Cohen (1981) worked on his meta- 
458

459

460

461

462

463

464

465

466

467

468

469

470

471

472

473

474

475

476

477

478

479

480

481

482

483

484

485

486

487

488

489

490

491

492

493

analysis of SET/learning correlations in multisection studies, he did not notice apparent COIs in many of these studies, and as we noted above, he himself had an interest in demonstrating the validity of SET/learning correlations as a measure of teaching effectiveness. P. A. Cohen's COI may explain why he did not notice strong evidence of small sample bias (Uttl et al., 2017) and why he disregarded dependence of SET/learning correlations on sample size even though reviewers of his meta-analysis were "concerned that rating/achievement correlations vary according to the number of sections used in the study" (P. A. Cohen, 1981, p. 303).

\section{Conclusions}

SET/learning correlations reported by multisection studies vary substantially with COI ties of the authors of these studies. Authors with ties to SET selling corporations, administration, and evaluation units found small to moderately large SET/learning correlations. In contrast, authors with no identifiable COIs found zero or near zero SET/learning correlations. The large variability in findings associated with COIs is troubling. Thousands of faculty members have been evaluated using SETs and many have had their careers terminated by SETs. Yet, the evidence is now clear that SETs do not measure teaching effectiveness (Uttl et al., 2017), are influenced by a number of teaching effectiveness irrelevant factors (TEIFs) not attributable to professors (e.g., student interest, student prior knowledge, subject matter, class size), and are also influenced by a number of faculty attributes -- sex, accent, national origin, beauty/hotness -- that universities are ill-advised to use in high stakes personnel decisions because use of such attributes is at minimum illegal.

Our findings highlight the need for openness and transparency, especially when research is likely to be used to support high stakes personnel decisions. At minimum, the COI ought to be clearly declared, including ownerships of shares in SET selling corporations and salaries derived from such activities, and data made available for other researchers wishing to verify reported findings. Although one may hope that P. A. Cohen's (1981) meta-analysis would not be published today without declaration of COI and without Cohen providing at minimum a list of all studies included in his meta-analysis, the SET/learning correlations he extracted for each study, and the number of sections each SET/learning correlation was based on, this is not guaranteed.

Finally, we need to encourage authors with no COI ties to conduct relevant research. As noted above, many newer multisection studies were conducted by authors from business and economics departments and by other authors with no COI ties. Without their contributions we may still erroneously believe that SET scores are valid measures of faculty's teaching effectiveness. 
Abrami, P. C., Cohen, P. A., \& d'Apollonia, S. (1988). Implementation problems in metaanalysis. Review of Educational Research, 58(2), 151-179. https://doi.org/10.2307/1170333

Abrami, P. C., \& d'Apollonia, S. (1999). Current concerns are past concerns. American Psychologist, 54(7), 519-520. https://doi.org/10.1037/0003-066X.54.7.519

Ahn, R., Woodbridge, A., Abraham, A., Saba, S., Korenstein, D., Madden, E., ... Keyhani, S. (2017). Financial ties of principal investigators and randomized controlled trial outcomes: cross sectional study. BMJ, 356, i6770. https://doi.org/10.1136/bmj.i6770

Armen. (2016, May 12). Aleamoni v. Commissioner of Internal Revenue. Retrieved from https://www.leagle.com/decision/intco20160512d37

Benton, S. E., \& Scott, O. (1976). A Comparison of the Criterion Validity of Two Types of Student Response Inventories for Appraising Instruction.

Benton, S. L., \& Cashin, W. E. (2012). Student ratings of teaching: A summary of research and literature. The IDEA Center.

Bernstein, D. A. (n.d.). A brief history of NITOP. Retrieved from nitop.org/History

Braskamp, L. A., Caulley, D., \& Costin, F. (1980). Student ratings and instructor self-ratings and their relationship to student achievement. American Educational Research Journal, 16(3), 295-306. https://doi.org/10.3102/00028312016003295

Centra, J. A. (1977). Student ratings of instruction and their relationship to student learning. American Educational Research Journal, 14(1), 17-24. https://doi.org/10.3102/00028312014001017

Centra, J. A. (2015). Student evaluation of instruction: Research evidence and their utility. Journal of Collective Bargaining in the Academy, 0(49), 1-4.

Chase, C. I., \& Keene, J. M. (1979). Validity of student ratings of faculty. Indiana Studies in Higher Education, Number Forty. Bureau of Evaluative Studies and Testing, Division of 
Research and Development, Indiana University, Bloomington, Indiana 47401.

Clayson, D. E. (2009). Student evaluations of teaching: Are they related to what students learn?: A meta-analysis and review of the literature. Journal of Marketing Education, 31(1), 16-30. https://doi.org/10.1177/0273475308324086

Cohen, P. A. (1980). A meta-analysis of the relationship between student ratings of instruction and student achievement.

Cohen, P. A. (1981). Student ratings of instruction and student achievement: A meta-analysis of multisection validity studies. Review of Educational Research, 51(3), 281-309. https://doi.org/10.3102/00346543051003281

Cohen, P. A. (1983). Comment on a selective review of the validity of student ratings of teaching. The Journal of Higher Education, 54(4), 448-458. https://doi.org/10.2307/1981907

Cohen, S. H., \& Berger, W. G. (1970). Dimensions of students' ratings of college instructors underlying subsequent achievement on course examinations. Proceedings. Presented at the 78th Annual Convention of Americal Psychological Association.

Davis, B. G. (2009). Tools for Teaching (2 edition). San Francisco, CA: Jossey-Bass.

Doyle, K. O. (1972). Construction and evaluation of scales for rating college instructors. ProQuest Dissertations Publishing.

Doyle, K. O., \& Crichton, L. I. (1978). Student, peer, and self evaluations of college instructors. Journal of Educational Psychology, 70(5), 815-26. https://doi.org/10.1037/00220663.70.5.815

Doyle, K. O., \& Whitely, S. E. (1974). Student ratings as criteria for effective teaching. American Educational Research Journal, 11(3), 259-274. https://doi.org/10.3102/00028312011003259

Elliott, D. N. (1950). Characteristics and relationships of various criteria of college and university teaching. In Studies in college and university staff evaluation (pp. 5-61). Lafayette, Ind.

Endo, G. T., \& Della - Piana, G. (1977). A validation study of course evaluation ratings. 
Improving College and University Teaching, r.

Feldman, K. A. (1989). The association between student ratings of specific instructional dimensions and student achievement: Refining and extending the synthesis of data from multisection validity studies. Research in Higher Education, 30(6), 583-645.

Frey, P. W., Leonard, D. W., \& Beatty, W. W. (1975). Student ratings of instruction: Validation research. American Educational Research Journal, 12(4), 435-444. https://doi.org/10.3102/00028312012004435

Greenwood, G. E., Bridges, C. M., Ware, W. B., \& Mclean, J. E. (1973). Student evaluation of college teaching behaviors instrument: A factor analysis. The Journal of Higher Education, 44(8), 596-604. https://doi.org/10.1080/00221546.1973.11776894

Greenwood, G. E., Hazelton, A., Smith, A., \& Ware, W. (1976). A study of the validity of four types of student ratings of college teaching assessed on a criterion of student achievement gains. Research in Higher Education, 5(2), 171-178. https://doi.org/10.1007/BF00992010

Hallgren, K. A. (2012). Computing inter-rater reliability for observational data: An overview and tutorial. Tutorials in Quantitative Methods for Psychology, 8(1), 23-34.

Harry Murray. (2004). Retrieved from www.stlhe.ca/awards/chris-knapper-award/2004-recipient/ Hill, W. (2006). Student evaluation of teaching - Myths and realities. Retrieved from https://peer.asee.org/student-evaluation-of-teaching-myths-and-realities.pdf Institute of Medicine (US) Committee on conflict of interest in medical research, education, and practice. (2009). Conflict of Interest in Medical Research, Education, and Practice (B. Lo \& M. J. Field, Eds.). Retrieved from http://www.ncbi.nlm.nih.gov/books/NBK22942/

Isaacson, R. L., Mckeachie, W. J., Milholland, J. E., Lin, Y. G., Hofeller, M., \& Zinn, K. L. (1964). Dimensions of student evaluations of teaching. Journal of Educational Psychology, 55(6), 344-351. https://doi.org/10.1037/h0042551

Junior Division Dean Assistant Named. (1970, June 15). M.U.N. Gazette. Retrieved from http://collections.mun.ca/PDFs/mun_gazette/MUNGaz_V02N20.pdf 
Kontopantelis, E., \& Reeves, D. (2012). Performance of statistical methods for meta-analysis when true study effects are non-normally distributed: A simulation study. Statistical Methods in Medical Research, 21(4), 409-426. https://doi.org/10.1177/0962280210392008

Kulik, J. A., Kulik, C.-L. C., \& Cohen, P. A. (1980). Effectiveness of computer-based college teaching: A meta-analysis of findings. Review of Educational Research, 50(4), 525-544. https://doi.org/10.2307/1170294

Marsh, H. W. (1980). Students' evaluations of college/university teaching: A Description of research and an Instrument.

Marsh, H. W. (2007). Students' evaluations of university teaching: Dimensionality, reliability, validity, potential biases and usefulness. In R. P. Perry \& J. C. Smart (Eds.), The Scholarship of Teaching and Learning in Higher Education: An Evidence-Based Perspective (pp. 319-383). https://doi.org/10.1007/1-4020-5742-3_9

Marsh, H. W., Fleiner, H., \& Thomas, C. S. (1975). Validity and usefulness of student evaluations of instructional quality. Journal of Educational Psychology, 67(6), 833-839. https://doi.org/10.1037/0022-0663.67.6.833

McCallum, L. W. (1984). A meta-analysis of course evaluation data and its use in the tenure decision. Research in Higher Education, 21(2), 150-158. https://doi.org/10.1007/BF00975102

Mckeachie, W. J., \& And Others. (1979). A small study assessing teacher effectiveness: Does learning last? Contemporary Educational Psychology, 3(4), 352-57. https://doi.org/10.1016/0361-476X(78)90037-1

McKeachie, W., Lin, Y.-G., \& Mann, W. (1971). Student ratings of teacher effectiveness: Validity studies. American Educational Research Journal, 8(3), 435-445. https://doi.org/10.3102/00028312008003435

Murray, H. G. (1983). Low-Inference classroom teaching behaviors and student ratings of college teaching effectiveness. Journal of Educational Psychology, 75(1), 138-49. 
https://doi.org/10.1037/0022-0663.75.1.138

Prosser, M., \& Trigwell, K. (1991). Student evaluations of teaching and courses: Student learning approaches and outcomes as criteria of validity. Contemporary Educational Psychology, 16(3), 293-301. https://doi.org/10.1016/0361-476X(91)90029-K

R Core Team. (2018). R: A language and environment for statistical computing. Retrieved from https://www.R-project.org/

Remmers, H. H., Martin, F. D., \& Elliott, D. N. (1949). Are students' ratings of instructors related to their grades? Purdue University Studies in Higher Education, 66, 17-26.

Solomon, D., Rosenberg, L., \& Bezdek, W. E. (1964). Teacher behavior and student learning. Journal of Educational Psychology, 55(1), 23-30. https://doi.org/10.1037/h0040516

Spooren, P., Brockx, B., \& Mortelmans, D. (2013). On the validity of student evaluation of teaching: The state of the art. Review of Educational Research, 83(4), 598-642. https://doi.org/10.3102/0034654313496870

Stark, P., \& Freishtat, R. (2014). An evaluation of course evaluations. ScienceOpen Research. https://doi.org/10.14293/S2199-1006.1.SOR-EDU.AOFRQA.v1

The Endeavor Handbook. (n.d.). Retrieved from https://theflorys.org/David.Flory/PDF_files/Endeavor_Handbook.pdf

Uttl, B., White, C. A., \& Gonzalez, D. W. (2017). Meta-analysis of faculty's teaching effectiveness: Student evaluation of teaching ratings and student learning are not related. Studies in Educational Evaluation, 54, 22-42.

https://doi.org/10.1016/j.stueduc.2016.08.007

Wachtel, H. K. (1998). Student evaluation of college teaching effectiveness: a brief review. Assessment \& Evaluation in Higher Education, 23(2), 191-212. https://doi.org/10.1080/0260293980230207

Whitely, S. E., \& Doyle, K. O. (1979). Validity and generalizability of student ratings from between-classes and within-class data. Journal of Educational Psychology, 71(1), 11724. https://doi.org/10.1037/0022-0663.71.1.117 
Yunker, P. J., \& Yunker, J. A. (2003). Are student evaluations of teaching valid? Evidence from an analytical business core course. Journal of Education for Business, 78(6), 313-317. https://doi.org/10.1080/08832320309598619 
Figure 1 (on next page)

Descriptive analyses of SET/learning correlations, sample size, and publication year.

(A) The magnitude of SET/learning correlations as a function of the multisection study size (see Uttl et al., 2017). (B) The histogram of multisection studies by year of publication. (C) The number of studies published prior to 1981 and since then by origin of the study. (D) Study size as a function of year of publication. 


\section{Figure 2 (on next page)}

SE/learning correlations as a function of publication time, COls, and authors' associations.

(A) The size of SET/learning correlations as function of publication date, prior to 1981 vs. 1981 and after. Each dot represents one SET/learning correlation superimposed on the boxplot of their distribution. (B) Boxplots of SET/learning correlations by authors' associations with SET corporations. (C) Boxplots of SET/learning correlations by authors' associations with SET corporations, administration, evaluation units, and authoring SET. For these analyses, studies were assigned in categories by the highest, most significant $\mathrm{COI}$ in the following order: corporate, administrative, evaluation unit, SET author, and no identified COl/other. (D) Boxplots of SET/learning correlations by authors associations with SET corporations, administration, evaluation units, psychology/education departments, business/economics departments, and other departments. Similarly to the previous analysis, the highest level association was used to categorize studies. 


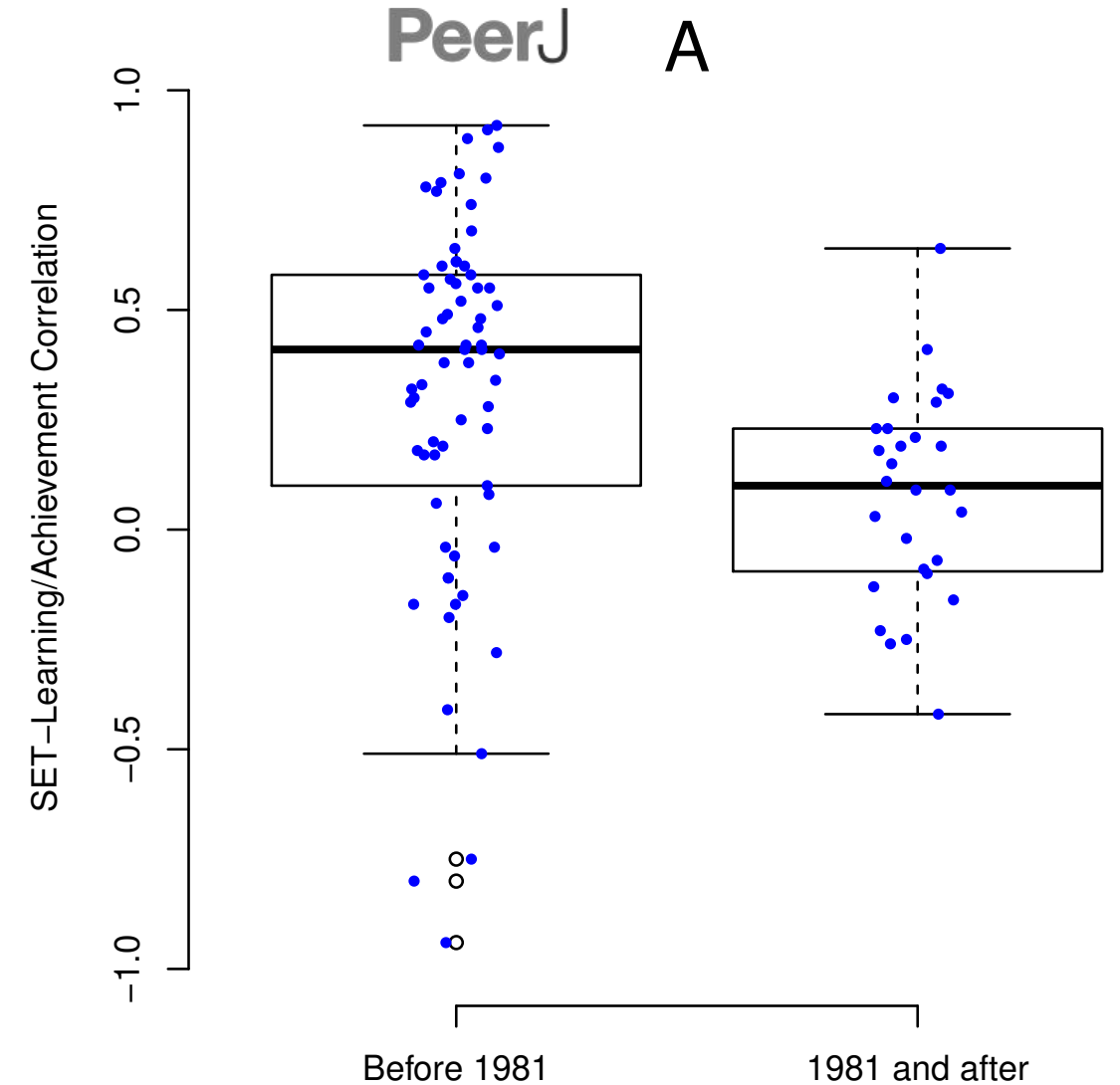

Publication Period

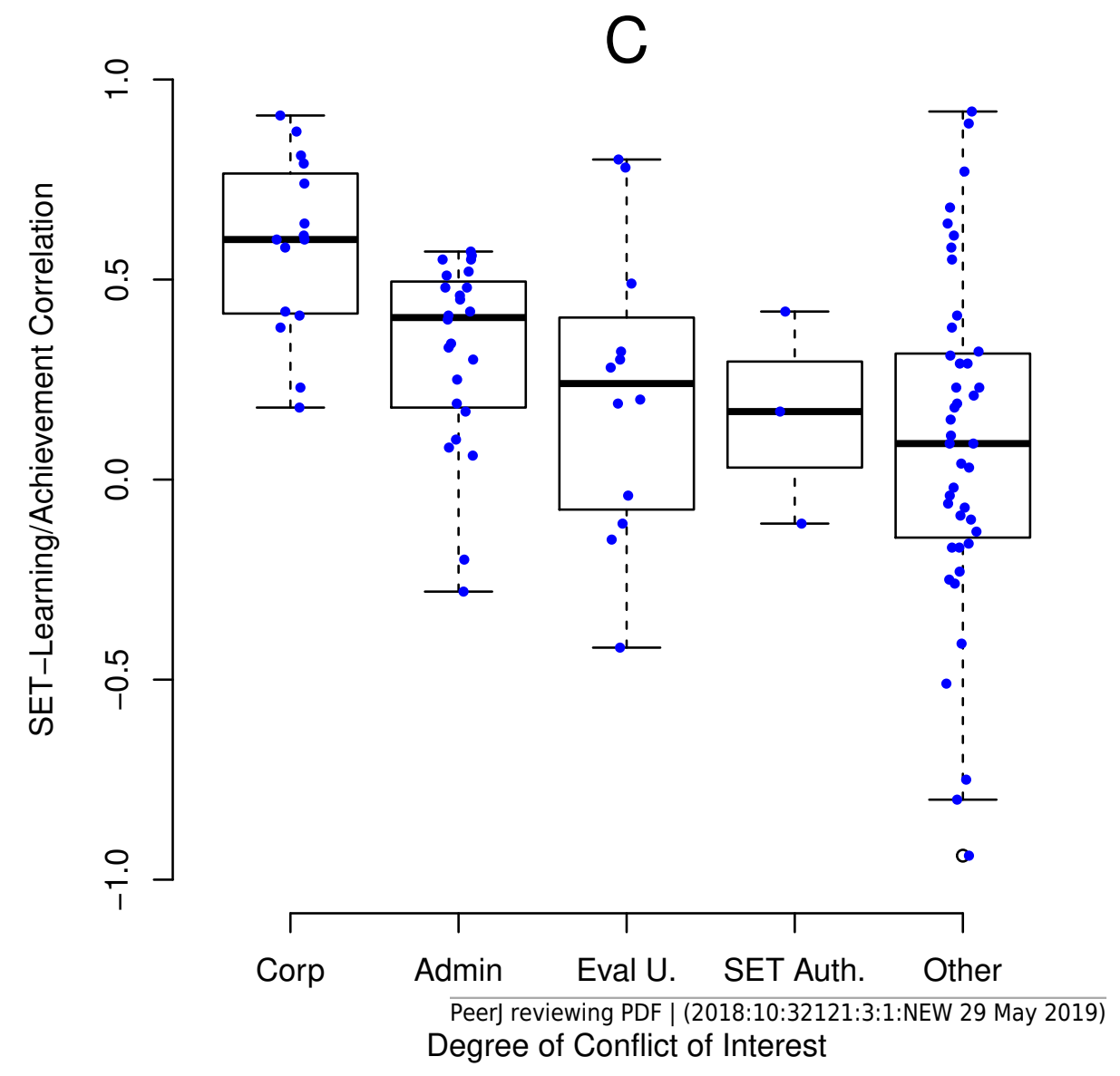

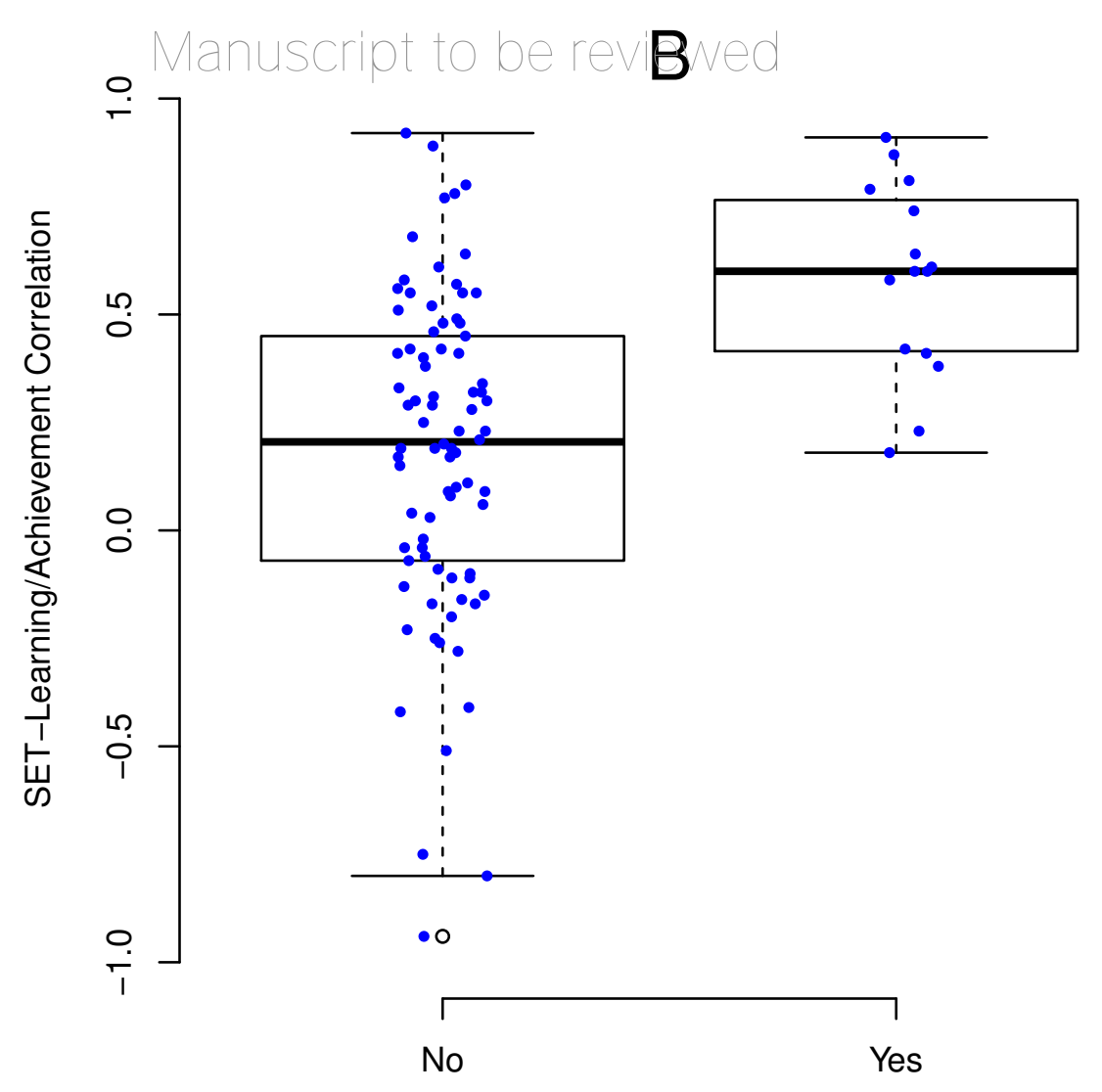

Author with SET Corp

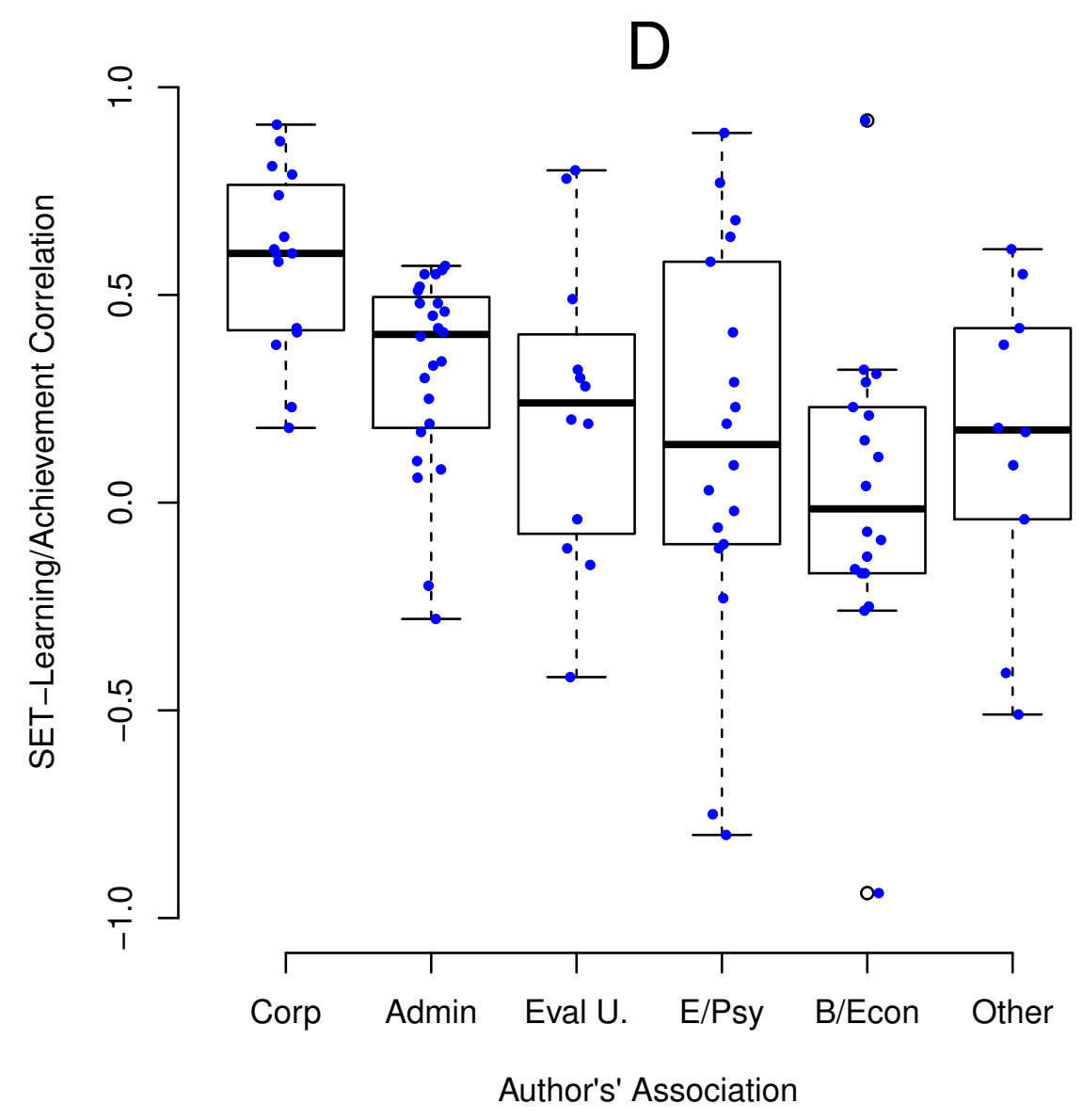


Figure 3 (on next page)

SET/learning correlations by the total number of COls identified for each study.

The figure shows SET/learning correlations as a function of number of COls. Each dot represents one SET/learning correlation superimposed on the boxplot of their distribution. 


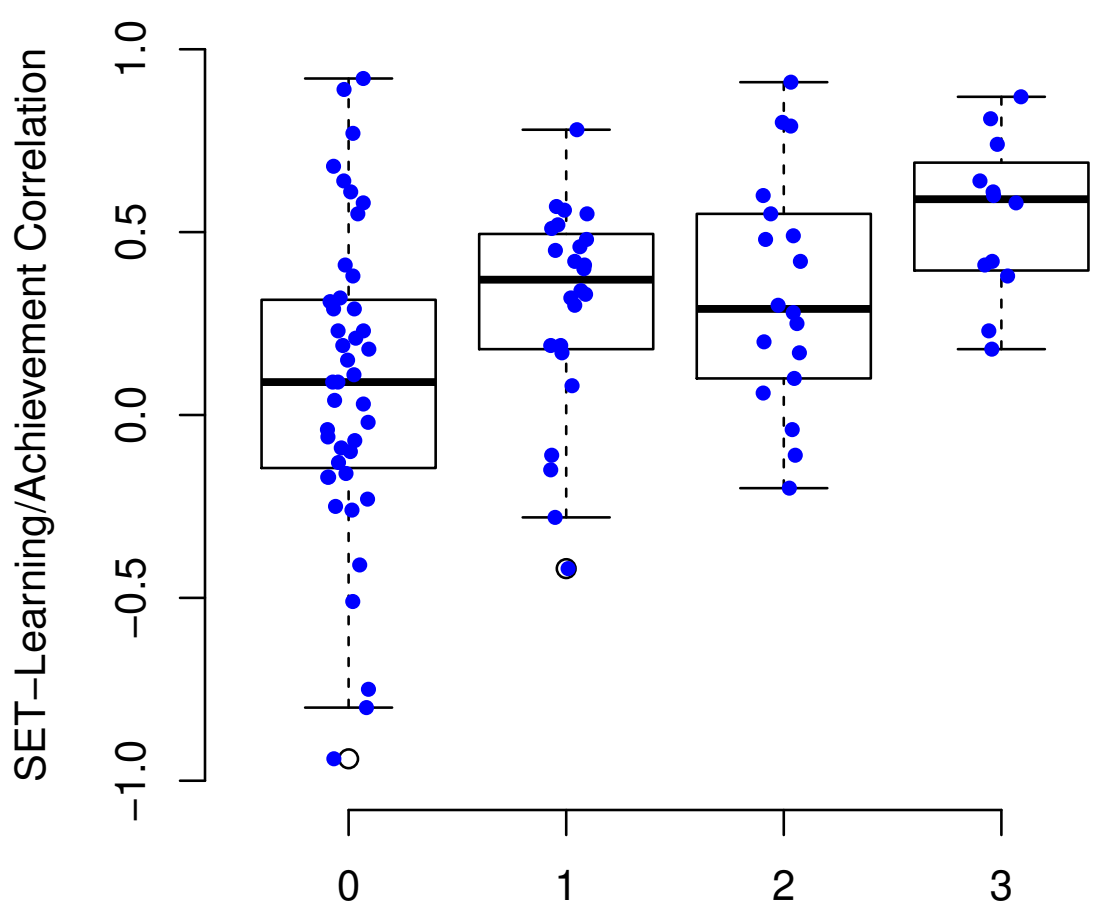

Number of COls 


\section{Table $\mathbf{1}$ (on next page)}

Studies included in Uttl et al.'s (2017) meta-analysis with identified COls and authors' associations with education and psychology departments, and business and economics departments. 
1 Table 1

2 Studies included in Uttl et al. 's (2017) meta-analysis with identified COIs and authors'

3 associations with education and psychology departments, and business and economics

4 departments.

\begin{tabular}{|c|c|c|c|c|c|c|c|c|c|c|}
\hline Study & $n$ & $r$ & Corp $^{1}$ & $\operatorname{Admin}^{2}$ & $\begin{array}{l}\text { Eval } \\
\text { U. }{ }^{3}\end{array}$ & $\begin{array}{l}\text { SET } \\
\text { Auth. } \\
4\end{array}$ & $\begin{array}{l}\text { Funder } \\
5\end{array}$ & $\begin{array}{l}\text { No. } \\
\text { of } \\
\text { COls }\end{array}$ & $\begin{array}{l}E / P s \\
y^{7}\end{array}$ & $\begin{array}{l}\mathrm{B} / \mathrm{Eco} \\
\mathrm{n}^{8}\end{array}$ \\
\hline Beleche.2012 & 82 & 0.21 & 0 & 0 & 0 & 0 & 0 & 0 & 0 & 1 \\
\hline Benbassat.1981 & 15 & 0.18 & 0 & 0 & 0 & 0 & 0 & 0 & 0 & 0 \\
\hline Bendig.1953a & 5 & 0.89 & 0 & 0 & 0 & 0 & 0 & 0 & 1 & 0 \\
\hline Bendig.1953b & 5 & -0.80 & 0 & 0 & 0 & 0 & 0 & 0 & 1 & 0 \\
\hline Benton.1976 & 31 & 0.17 & 0 & 0 & 0 & $1^{\mathrm{s} 1}$ & 0 & 1 & 0 & 0 \\
\hline Bolton.1979 & 10 & 0.68 & 0 & 0 & 0 & 0 & 0 & 0 & 1 & 0 \\
\hline Braskamp.1979.01 & 19 & 0.17 & 0 & $1^{\mathrm{A} 1}$ & $1^{\mathrm{E} 1}$ & 0 & 0 & 2 & 0 & 0 \\
\hline Braskamp.1979.02 & 17 & 0.48 & 0 & $1^{\mathrm{A} 1}$ & $1^{\mathrm{E} 1}$ & 0 & 0 & 2 & 0 & 0 \\
\hline Bryson.1974 & 20 & 0.55 & 0 & 0 & 0 & 0 & 0 & 0 & 0 & 0 \\
\hline Capozza.1973 & 8 & -0.94 & 0 & 0 & 0 & 0 & 0 & 0 & 0 & 1 \\
\hline Centra.1977.01 & 7 & 0.60 & $1^{\mathrm{C} 1}$ & 0 & $1 \mathrm{E} 2$ & $1^{\mathrm{s} 2}$ & 0 & 3 & 0 & 0 \\
\hline Centra.1977.02 & 7 & 0.61 & $1^{\mathrm{C} 1}$ & 0 & $1 \mathrm{E} 2$ & $1^{\mathrm{s} 2}$ & 0 & 3 & 0 & 0 \\
\hline Centra.1977.03 & 22 & 0.64 & $1^{\mathrm{C} 1}$ & 0 & $1 \mathrm{E} 2$ & $1^{\mathrm{s} 2}$ & 0 & 3 & 0 & 0 \\
\hline Centra.1977.04 & 13 & 0.23 & $1^{\mathrm{C} 1}$ & 0 & $1 \mathrm{E} 2$ & $1^{\mathrm{s} 2}$ & 0 & 3 & 0 & 0 \\
\hline Centra.1977.05 & 8 & 0.87 & $1^{\mathrm{C} 1}$ & 0 & $1 \mathrm{E} 2$ & $1^{\mathrm{s} 2}$ & 0 & 3 & 0 & 0 \\
\hline Centra.1977.06 & 7 & 0.58 & $1^{\mathrm{C} 1}$ & 0 & $1 \mathrm{E} 2$ & $1^{\mathrm{s} 2}$ & 0 & 3 & 0 & 0 \\
\hline Centra.1977.07 & 8 & 0.41 & $1^{\mathrm{C} 1}$ & 0 & $1 \mathrm{E} 2$ & $1^{\mathrm{s} 2}$ & 0 & 3 & 0 & 0 \\
\hline Chase.1979.01 & 8 & 0.78 & 0 & 0 & $1 \mathrm{E} 3$ & 0 & 0 & 1 & 0 & 0 \\
\hline Chase.1979.02 & 6 & 0.19 & 0 & 0 & $1^{\mathrm{E} 3}$ & 0 & 0 & 1 & 0 & 0 \\
\hline Cohen.1970 & 25 & 0.42 & 0 & 0 & 0 & $1^{\mathrm{s} 3}$ & $1^{\mathrm{F} 1}$ & 2 & 0 & 0 \\
\hline Costin.1978.01 & 25 & 0.52 & 0 & $1^{\mathrm{A} 2}$ & 0 & 0 & 0 & 1 & 1 & 0 \\
\hline Costin.1978.02 & 25 & 0.56 & 0 & $1^{\mathrm{A} 2}$ & 0 & 0 & 0 & 1 & 1 & 0 \\
\hline Costin.1978.03 & 21 & 0.46 & 0 & $1^{\mathrm{A} 2}$ & 0 & 0 & 0 & 1 & 1 & 0 \\
\hline Costin.1978.04 & 25 & 0.41 & 0 & $1^{\mathrm{A} 2}$ & 0 & 0 & 0 & 1 & 1 & 0 \\
\hline Doyle.1974 & 12 & 0.49 & 0 & 0 & $1 \mathrm{E} 4$ & $1^{\text {s4 }}$ & 0 & 2 & 0 & 0 \\
\hline
\end{tabular}




\begin{tabular}{|c|c|c|c|c|c|c|c|c|c|}
\hline Doyle.1978 & 10 & -0.04 & 0 & 0 & $1 \mathrm{E} 4$ & $1^{\text {s4 }}$ & 0 & 2 & 0 \\
\hline Drysdale.2010.01 & 11 & 0.09 & 0 & 0 & 0 & 0 & 0 & 0 & 1 \\
\hline Drysdale.2010.02 & 10 & -0.02 & 0 & 0 & 0 & 0 & 0 & 0 & 1 \\
\hline Drysdale.2010.03 & 8 & 0.64 & 0 & 0 & 0 & 0 & 0 & 0 & 1 \\
\hline Drysdale.2010.04 & 11 & 0.03 & 0 & 0 & 0 & 0 & 0 & 0 & 1 \\
\hline Drysdale.2010.05 & 10 & -0.23 & 0 & 0 & 0 & 0 & 0 & 0 & 1 \\
\hline Drysdale.2010.06 & 12 & -0.1 & 0 & 0 & 0 & 0 & 0 & 0 & 1 \\
\hline Drysdale.2010.07 & 11 & 0.19 & 0 & 0 & 0 & 0 & 0 & 0 & 1 \\
\hline Drysdale.2010.08 & 16 & 0.41 & 0 & 0 & 0 & 0 & 0 & 0 & 1 \\
\hline Drysdale.2010.09 & 11 & 0.23 & 0 & 0 & 0 & 0 & 0 & 0 & 1 \\
\hline Elliot.1950 & 36 & 0.32 & 0 & 0 & $1^{\mathrm{E} 5}$ & 0 & 0 & 1 & 0 \\
\hline Ellis.1977 & 19 & 0.58 & 0 & 0 & 0 & 0 & 0 & 0 & 1 \\
\hline Endo.1976 & 5 & -0.15 & 0 & 0 & $1 \mathrm{E} 6$ & 0 & 0 & 1 & 0 \\
\hline Fenderson.1997 & 29 & 0.09 & 0 & 0 & 0 & 0 & 0 & 0 & 0 \\
\hline Frey.1973.01 & 8 & 0.91 & $1^{\mathrm{C} 2}$ & 0 & 0 & $1^{\text {s5 }}$ & 0 & 2 & 0 \\
\hline Frey.1973.02 & 5 & 0.6 & $1^{\mathrm{C} 2}$ & 0 & 0 & 1 s5 & 0 & 2 & 0 \\
\hline Frey.1975.01 & 9 & 0.81 & $1^{\mathrm{C} 2}$ & 0 & 0 & $1^{\text {s5 }}$ & $1^{F 2}$ & 3 & 0 \\
\hline Frey.1975.02 & 12 & 0.18 & $1^{\mathrm{C} 2}$ & 0 & 0 & $1^{\text {s5 }}$ & $1 F 2$ & 3 & 0 \\
\hline Frey.1975.03 & 5 & 0.74 & $1^{\mathrm{C} 2}$ & 0 & 0 & 1 s5 & $1^{F 2}$ & 3 & 0 \\
\hline Frey.1976 & 7 & 0.79 & $1^{\mathrm{C} 2}$ & 0 & 0 & $1^{\text {s5 }}$ & 0 & 2 & 1 \\
\hline Galbraith.2012a.01 & 8 & 0.23 & 0 & 0 & 0 & 0 & 0 & 0 & 0 \\
\hline Galbraith.2012a.02 & 10 & 0.32 & 0 & 0 & 0 & 0 & 0 & 0 & 0 \\
\hline Galbraith.2012a.03 & 12 & -0.07 & 0 & 0 & 0 & 0 & 0 & 0 & 0 \\
\hline Galbraith.2012a.04 & 8 & 0.31 & 0 & 0 & 0 & 0 & 0 & 0 & 0 \\
\hline Galbraith.2012a.05 & 8 & -0.13 & 0 & 0 & 0 & 0 & 0 & 0 & 0 \\
\hline Galbraith.2012a.06 & 9 & -0.16 & 0 & 0 & 0 & 0 & 0 & 0 & 0 \\
\hline Galbraith.2012a.07 & 13 & 0.11 & 0 & 0 & 0 & 0 & 0 & 0 & 0 \\
\hline Galbraith.2012b & 5 & 0.29 & 0 & 0 & 0 & 0 & 0 & 0 & 0 \\
\hline Greenwood.1976 & 36 & -0.11 & 0 & 0 & 0 & $1^{\mathrm{S} 6}$ & 0 & 1 & 1 \\
\hline Grush.1975 & 18 & 0.45 & 0 & $1^{\mathrm{A} 3}$ & 0 & 0 & 0 & 1 & 0 \\
\hline
\end{tabular}




\begin{tabular}{|c|c|c|c|c|c|c|c|c|c|}
\hline Hoffman.1978.03 & 75 & 0.29 & 0 & 0 & 0 & 0 & 0 & $c$ & 1 \\
\hline Koon.1995 & 36 & 0.3 & 0 & $1^{\mathrm{A} 4}$ & 0 & $1^{s 7}$ & 0 & 2 & 1 \\
\hline Marsh.1975 & 18 & 0.42 & $1^{\mathrm{C} 3}$ & 0 & $1 \mathrm{E7}$ & $1^{\mathrm{s} 8}$ & 0 & 3 & 0 \\
\hline Marsh.1980 & 31 & 0.38 & $1^{\mathrm{C} 3}$ & 0 & $1 \mathrm{E} 7$ & $1^{58}$ & 0 & 3 & 0 \\
\hline McKeachie.1971.01 & 34 & 0.06 & 0 & $1^{\mathrm{A} 5}$ & 0 & $1^{59}$ & 0 & 2 & 1 \\
\hline McKeachie.1971.02 & 32 & -0.20 & 0 & $1^{\mathrm{A} 5}$ & 0 & $1^{59}$ & 0 & 2 & 1 \\
\hline McKeachie.1971.03 & 6 & 0.10 & 0 & $1^{\mathrm{A} 5}$ & 0 & $1^{\mathrm{s} 9}$ & 0 & & 1 \\
\hline McKeachie.1971.04 & 16 & 0.25 & 0 & $1^{\mathrm{A} 5}$ & 0 & $1^{\text {s9 }}$ & 0 & 2 & 1 \\
\hline McKeachie.1971.05 & 18 & 0.55 & 0 & $1^{\mathrm{A} 5}$ & 0 & $1^{59}$ & 0 & 2 & 1 \\
\hline McKeachie.1978 & 6 & 0.20 & 0 & 0 & $1 \mathrm{E} 8$ & $1^{\mathrm{s} 9}$ & 0 & 2 & 0 \\
\hline Mintzes.1977 & 25 & 0.38 & 0 & 0 & 0 & 0 & 0 & $c$ & 0 \\
\hline Morgan.1978 & 5 & 0.92 & 0 & 0 & 0 & 0 & 0 & ( & 0 \\
\hline Murdock.1969 & 6 & 0.77 & 0 & 0 & 0 & 0 & 0 & ( & 1 \\
\hline Orpen.1980 & 10 & 0.61 & 0 & 0 & 0 & 0 & 0 & ( & 0 \\
\hline Palmer.1978 & 14 & -0.17 & 0 & 0 & 0 & 0 & 0 & ( & 0 \\
\hline Prosser.1991 & 11 & -0.42 & 0 & 0 & $1 \mathrm{E} 9$ & 0 & 0 & 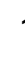 & 0 \\
\hline Rankin.1965 & 21 & -0.06 & 0 & 0 & 0 & 0 & 0 & ( & 1 \\
\hline Remmers.1949 & 53 & 0.28 & 0 & 0 & 1E10 & $1^{S 10}$ & 0 & 2 & 0 \\
\hline Rodin.1972 & 12 & -0.75 & 0 & 0 & 0 & 0 & 0 & ( & 1 \\
\hline Sheets. 1995.01 & 58 & 0.15 & 0 & 0 & 0 & 0 & 0 & ( & 0 \\
\hline Sheets. 1995.02 & 63 & -0.25 & 0 & 0 & 0 & 0 & 0 & ( & 0 \\
\hline Solomon.1964 & 24 & 0.30 & 0 & 0 & 1E11 & 0 & 0 & 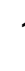 & 0 \\
\hline Soper.1973 & 14 & -0.17 & 0 & 0 & 0 & 0 & 0 & ( & 0 \\
\hline Sullivan.1974.01 & 14 & 0.51 & 0 & $1^{\mathrm{A} 6}$ & 0 & 0 & 0 & 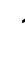 & 0 \\
\hline Sullivan.1974.04 & 9 & 0.57 & 0 & $1^{\mathrm{A} 6}$ & 0 & 0 & 0 & 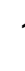 & 0 \\
\hline Sullivan.1974.05 & 9 & 0.33 & 0 & $1^{\mathrm{A} 6}$ & 0 & 0 & 0 & 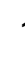 & 0 \\
\hline Sullivan.1974.06 & 16 & 0.34 & 0 & $1^{\mathrm{A} 6}$ & 0 & 0 & 0 & 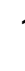 & 0 \\
\hline Sullivan.1974.07 & 8 & 0.48 & 0 & $1^{\mathrm{A} 6}$ & 0 & 0 & 0 & 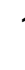 & 0 \\
\hline Sullivan.1974.08 & 6 & 0.55 & 0 & $1^{\mathrm{A} 6}$ & 0 & 0 & 0 & & 0 \\
\hline Sullivan.1974.09 & 8 & 0.08 & 0 & $1^{\mathrm{A} 6}$ & 0 & 0 & 0 & & 0 \\
\hline
\end{tabular}




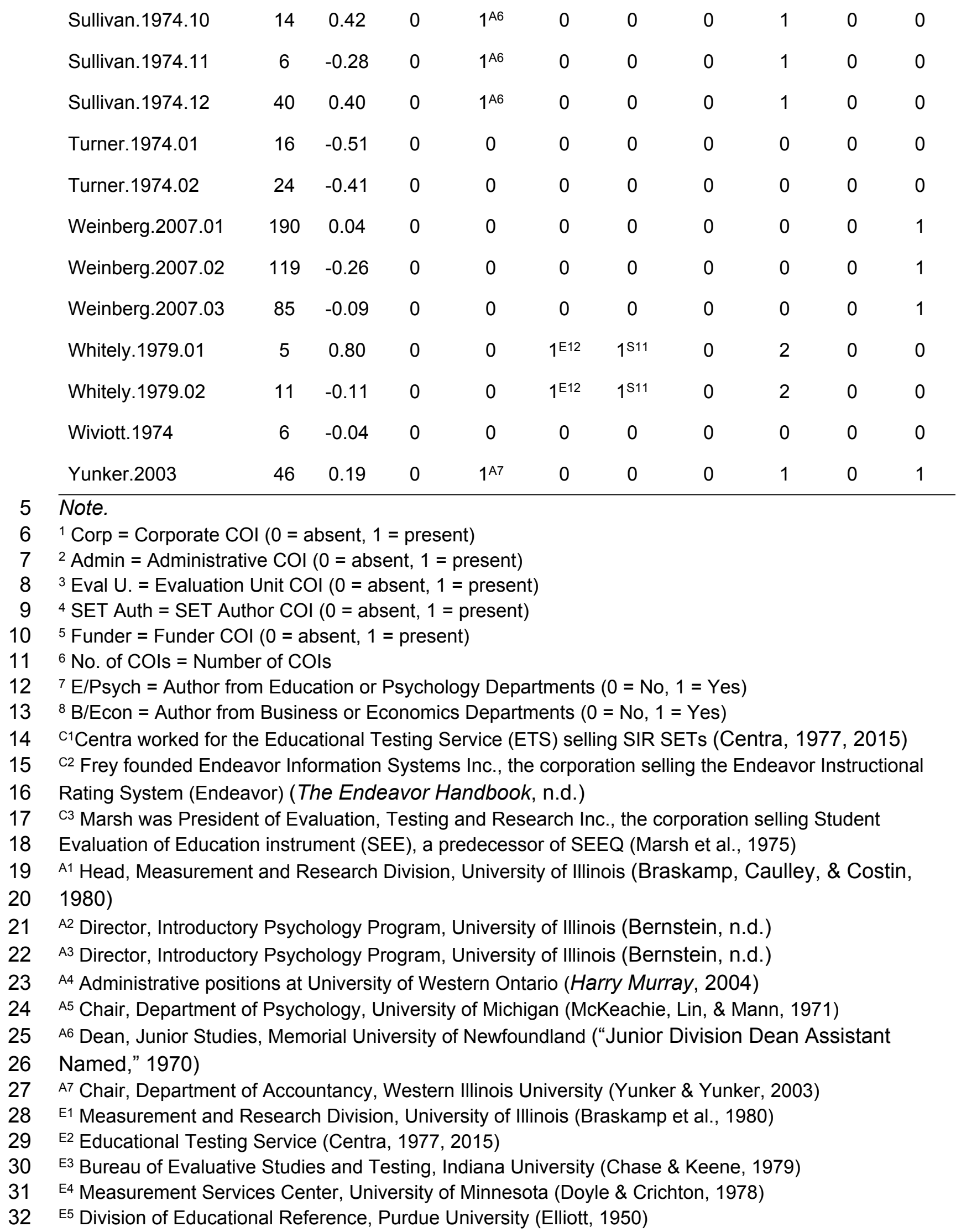


33 E6 Bureau of Educational Research and Center to Improve Learning and Instruction (Endo \& Della 34 Piana, 1977)

$35 \quad{ }^{\text {E7 }}$ Evaluation, Testing and Research Inc. (Marsh et al., 1975) and Evaluation Services, University of 36 Southern California (Marsh, 1980)

37 E8 Center for Research on Learning and Teaching, University of Michigan (Mckeachie \& And Others, 38 1979)

39 E9 Center for Learning and Teaching, University of Technology, Sydney (Prosser \& Trigwell, 1991)

40 E10 Division of Educational Reference, Purdue University (Remmers, Martin, \& Elliott, 1949)

41 E11 Center for the Study of Liberal Education for Adults, Chicago (Solomon, Rosenberg, \& Bezdek, 1964)

42 E12 Measurement Services Center, University of Minnesota (Whitely \& Doyle, 1979)

43 S1 Scott developed the Inventory of Student Perception of Instruction (ISPI) (S. E. Benton \& Scott, 1976)

44 S2 Centra developed Student Instructional Report (SIR) while working for ETS (Centra, 2015)

45 s3 S. H. Cohen and Berger developed Student Instructional Rating Report (SIRR) (S. H. Cohen

46 \& Berger, 1970)

47 S4 Doyle developed Student Opinion Survey (SOS) (Doyle, 1972; Doyle \& Crichton, 1978; Doyle \&

48 Whitely, 1974)

49 s5 Frey developed The Endeavor Instructional Rating System (The Endeavor Handbook, n.d.)

50 s6 Greenwood co-developed the Student Evaluation of College Teaching Behaviors (SECTB)

51 (Greenwood, Bridges, Ware, \& Mclean, 1973; Greenwood, Hazelton, Smith, \& Ware, 1976)

$52 \quad$ S7 Murray developed Teacher Behaviors Inventory (TBI) (Murray, 1983)

53 s8 Marsh developed Students' Evalaution of Educational Quality (SEEQ) (Marsh, 1980; Marsh et al., 54 1975)

55 s9 McKeachie co-developed Student Perception of Teaching and Teacher (SPTT) (Isaacson et al., 1964;

56 McKeachie \& And Others, 1979)

57 S10 Remmers co-developed Purdue Rating Scale (PRS) (Remmers et al., 1949)

$58 \quad$ S11 Doyle developed Student Opinion Survey (SOS) (Doyle, 1972; Whitely \& Doyle, 1979)

$59 \quad$ F1 Funded by Education Developmental Program, Training Services, and Evaluation Services, Michigan

60 State University (S. H. Cohen \& Berger, 1970)

61 F2 Funded in part by Endeavor Information Systems Inc. (Frey, Leonard, \& Beatty, 1975)

62

63 


\section{Table 2 (on next page)}

Means, standard deviations, and correlations among key variables. 
1 Table 2

2 Means, standard deviations, and correlations among key variables.

3

\begin{tabular}{|c|c|c|c|c|c|c|c|c|c|c|c|c|}
\hline & $M$ & $S D$ & 1. & 2. & 3. & 4. & 5. & 6. & 7. & 8. & 9. & 10. \\
\hline 1. $n$ & 20.86 & 25.91 & & & & & & & & & & \\
\hline 2. $r$ & .24 & .38 & -.17 & & & & & & & & & \\
\hline 3. $1981+1$ & .29 & .46 & .29 & -.27 & & & & & & & & \\
\hline 4. Corp² & .15 & .36 & -.16 & .38 & -.27 & & & & & & & \\
\hline 5. Admin ${ }^{3}$ & .25 & .43 & -.03 & .12 & -.26 & -.25 & & & & & & \\
\hline 6. Eval U. ${ }^{4}$ & .24 & .43 & -.13 & .16 & -.30 & .36 & -.21 & & & & & \\
\hline 7. SET Auth. ${ }^{5}$ & .31 & .46 & -.11 & .27 & -.38 & .64 & -.07 & .41 & & & & \\
\hline 8. Funder 6 & .04 & .20 & -.07 & .16 & -.13 & .34 & -.12 & -.12 & .31 & & & \\
\hline 9. COI count ${ }^{7}$ & .99 & 1.07 & -.18 & .39 & -.51 & .73 & .19 & .60 & .85 & .34 & & \\
\hline 10. E/Psy ${ }^{8}$ & .30 & .46 & -.06 & -.03 & .08 & -.22 & .15 & -.36 & -.05 & -.14 & -.21 & \\
\hline 11. $\mathrm{B} / \mathrm{Econ}^{9}$ & .20 & .40 & .36 & -.28 & .55 & -.21 & -.22 & -.28 & -.33 & -.10 & -.44 & -.32 \\
\hline
\end{tabular}

4 Note. Correlations with $p<.05$ are printed in bold.

$5 \quad 11981+=$ Study was published 1981 or later $(0=$ No, $1=$ Yes $)$

$6 \quad{ }^{2}$ Corp $=$ Corporate $\mathrm{COI}(0=$ absent, $1=$ present $)$

$7 \quad{ }^{3}$ Admin $=$ Administrative $\mathrm{COI}(0=$ absent, $1=$ present $)$

$8{ }^{4}$ Eval U. = Evaluation Unit $\mathrm{COI}(0=$ absent, $1=$ present $)$

$9 \quad{ }^{5}$ SET Auth $=$ SET Author COI $(0=$ absent, $1=$ present $)$

$10{ }^{6}$ Funder $=$ Funder $\mathrm{COI}(0=$ absent, $1=$ present $)$

$11{ }^{7} \mathrm{COI}$ count $=$ Number of $\mathrm{COls}$

$12{ }^{8} \mathrm{E} /$ Psych $=$ Author from Education or Psychology Departments $(0=$ No, $1=$ Yes $)$

$13{ }^{9} \mathrm{~B} / \mathrm{Econ}=$ Author from Business or Economics Departments $(0=\mathrm{No}, 1=$ Yes $)$ 


\section{Table 3 (on next page)}

Random effect meta-analysis of SET/learning correlations by authors' associations with the most significant COI: Subgroup results. 
1 Table 3

2 Random effect meta-analysis of SET/learning correlations by authors' associations with the

3 most significant COI: Subgroup results.

\begin{tabular}{lccccc}
\hline Authors' association & $k$ & $r$ & $95 \% \mathrm{Cl}$ & $Q$ & $I^{2}$ \\
\hline Corporate & 15 & .57 & {$[.41, .70]$} & 14.85 & $5.8 \%$ \\
Administrative & 24 & .33 & {$[.21, .45]$} & 21.76 & $0 \%$ \\
Evaluation unit & 12 & .25 & {$[.03, .44]$} & 11.53 & $4.6 \%$ \\
SET author & 3 & .15 & {$[-.16, .43]$} & 4.18 & $52.1 \%$ \\
None & 43 & .06 & {$[-.04, .16]$} & 105.30 & $60.1 \%$ \\
\hline
\end{tabular}

4 


\section{Table 4 (on next page)}

Random effect meta-analysis of SET/learning correlations by authors' associations with the most significant unit/department: Subgroup results. 
1 Table 4

2 Random effect meta-analysis of SET/learning correlations by authors' associations with the

3 most significant unit/department: Subgroup results.

\begin{tabular}{lccccc}
\hline Authors' association/COI & $k$ & $r$ & $95 \% \mathrm{Cl}$ & $Q$ & $R^{2}$ \\
\hline Corporate & 15 & .57 & {$[.41, .70]$} & 14.85 & $5.8 \%$ \\
Administrative & 24 & .33 & {$[.21, .45]$} & 21.76 & $0 \%$ \\
Evaluation unit & 12 & .25 & {$[.04, .44]$} & 11.53 & $4.6 \%$ \\
Education/Psychology & 18 & .15 & {$[-.02, .31]$} & 36.88 & $53.9 \%$ \\
Business/Economics & 18 & -.04 & {$[-.18, .10]$} & 39.88 & $57.4 \%$ \\
Other & 10 & .16 & {$[-.04, .34]$} & 23.26 & $61.3 \%$
\end{tabular}

4

5 


\section{Table 5 (on next page)}

Random effect meta-analysis of SET/learning correlations by number of COls present: Subgroup results. 
1 Table 5

2 Random effect meta-analysis of SET/learning correlations by number of COIs present:

3 Subgroup results.

\begin{tabular}{lccccc}
\hline Number of COIs & $k$ & $r$ & $95 \% \mathrm{Cl}$ & $Q$ & $R^{2}$ \\
\hline 0 & 43 & .06 & {$[-.05, .16]$} & 105.30 & $60.1 \%$ \\
1 & 24 & .33 & {$[.20, .45]$} & 23.88 & $3.7 \%$ \\
2 & 18 & .30 & {$[.14, .44]$} & 26.25 & $35.2 \%$ \\
3 & 12 & .53 & {$[.34, .67]$} & 9.50 & $0 \%$ \\
\hline
\end{tabular}

4

5 